\title{
Echocardiologic evaluation and follow-up of cardiovascular complications in children with scorpion sting in coastal South India
}

\author{
Chandra Mohan Kumar, S. V. Naveen Prasad ${ }^{1}$
}

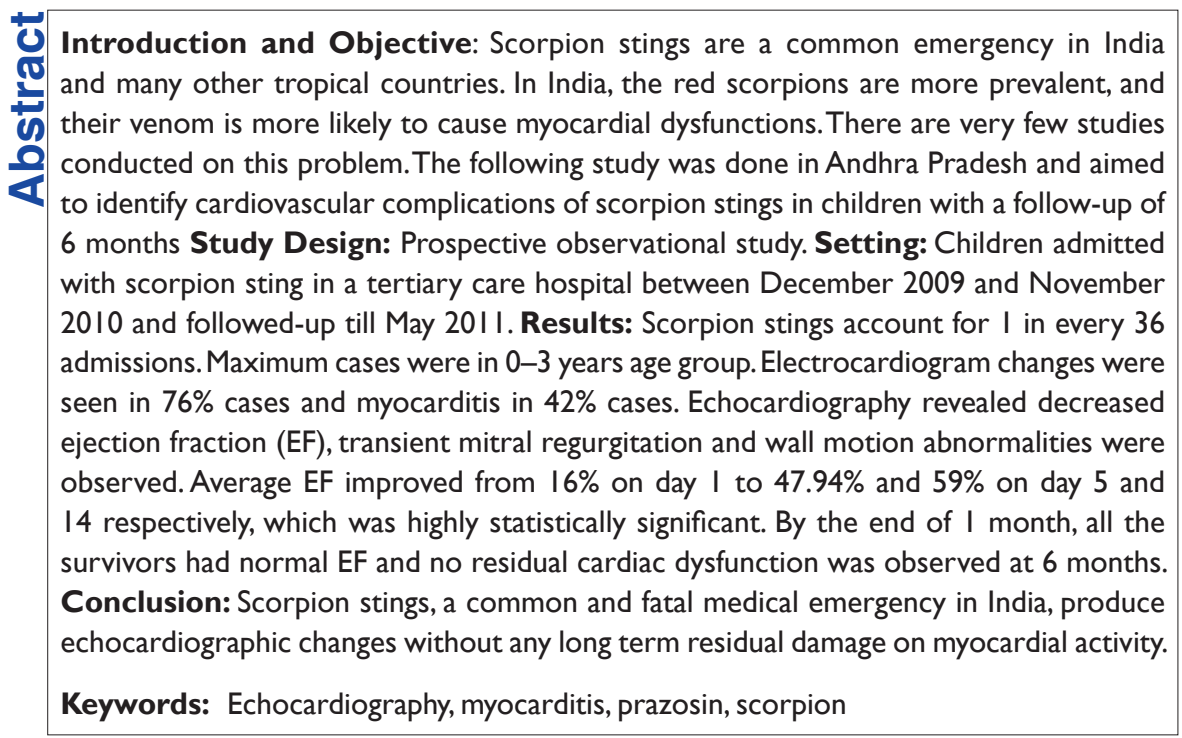

\begin{tabular}{|l|}
\hline Access this article online \\
\hline Website: www.ijccm.org \\
\hline DOI: 10.4103/0972-5229.148645 \\
\hline Quick Response Code: \\
\hline
\end{tabular}

\section{Introduction}

Scorpion stings are a major public health problem in pediatric practice in many tropical countries including India. For every person killed by poisonous snake, around ten are killed by a poisonous scorpion. ${ }^{[1]}$ Although the exact incidence of scorpion stings is not known, it is estimated that the annual number of scorpion stings exceeds 1.2 million with 2.3 billion population at risk world-wide. ${ }^{[2]}$

In India, Israel, Brazil and Mexico, cardiac manifestations after a scorpion sting is common. In Iran, tissue

\section{From:}

Department of Pediatrics, Hamdard Institute of Medical Sciences and

Research, Jamia Hamdard, New Delhi, 'Department of Pediatrics,

Rainbow Childrens Hospital, Kurnool, Andhra Pradesh, India

Correspondence:

Dr. Chandra Mohan Kumar, Flat No. 1103, BPTP Park, Grandeura, Sector 82 Faridabad, Haryana - 121 005, India

E-mail: cmkumar1@ rediffmail.com necrosis and hemolysis predominate. Neurological manifestations are prominent in United States of America and South Africa, while acute pancreatitis is the principal manifestation in Trinidad. ${ }^{[2-4]}$

Cardiovascular complications are the most important manifestations of Indian red scorpion envenomation. A full spectrum from hypotension and peripheral circulatory collapse to hypertension leading to stroke has been observed. Initially within 1-2 h of sting hypotension and bradycardia (cholinergic stimulation), are encountered followed by hypotension and tachycardia between 4 and $48 \mathrm{~h}$ due to severe left ventricular dysfunction and hypotension alone with good volume pulse and warm extremities is observed later in the recovery stage. Acute pulmonary edema (APE) complicates around $3-24.5 \%$ of all scorpion stings and is a leading cause of mortality in these patients, accounting for around $30 \%$ of fatalities. 
The clinical picture evolves within $30 \mathrm{~min}$ to $6 \mathrm{~h}$ after the sting. Hypertensive stress, direct toxic effects of the venom on the myocardium and catecholamine-induced myocardial injury; all contribute to rhythm disturbance and left ventricular failure. The myocardial injury is exacerbated by free fatty acid and free radical accumulation and hyperkalemia. ${ }^{[5-7]}$ Incidence of myocarditis has been reported to be around $22-33 \%{ }^{[8]}$ However, a case series from Chennai, reported peripheral circulatory failure and hypotension initially, with myocarditis observed only during follow-up. ${ }^{[9]}$

This study was conducted as an observational case series to note the cardiovascular complications and subsequent echocardiographic evaluation following scorpion stings and a follow-up of the cases with myocarditis for a period of 6 months after the discharge was taken up.

\section{Subjects and Methods}

\section{Study design}

Prospective observational study.

\section{Setting}

Children admitted with scorpion sting in a tertiary care hospital between December 2009 and November 2010 and followed-up till May 2011.

\section{The study population}

Children with scorpion sting admitted in the pediatric ward and psychiatric intensive care unit (PICU) between December 1, 2009 and November 30, 2010.

Patient was considered suffering from myocarditis if there was tachycardia, gallop rhythm, muffled heart sounds, electrocardiogram (ECG) changes, that is, low amplitude, ST-segment changes, presence of arrhythmias and cardiomegaly in chest radiograph. APE was diagnosed on the basis of the presence of tachypnea, bilateral crepitations in lung and suggestive chest radiograph.

On admission, a detailed clinical history, including the time of sting, symptomatology, details of treatment received before admission and description of the scorpion obtained. Hourly monitoring of heart rate, respiratory rate, blood pressure, urine output, cardiovascular and respiratory status was done. Routine investigations like complete blood counts, peripheral smear, urinalysis, bleeding time, clotting time, blood sugar, chest X-ray, ECG were done in all cases. Cases with clinical or ECG evidence of cardiovascular complications were admitted in PICU and were subjected to echocardiography by portable echocardiography machine. In cases with evidence of myocarditis and congestive cardiac failure (CCF), ECG and $2 \mathrm{D}$ echocardiography were repeated on $5^{\text {th }}$ day.

All patients received a dose of prazosin $(30 \mu \mathrm{g} / \mathrm{kg} / \mathrm{dose})$, at admission. Children with peripheral circulatory failure were treated with prazosin, intravenous (IV) fluids, and IV diazepam $(0.2 \mathrm{mg} / \mathrm{kg})$. Prazosin was repeated every $4 \mathrm{~h}$, till peripheries became warm and urine output improved. Myocarditis with CCF was treated with oxygen (0.5-2 L/min), maintainence IV fluids, prazosin $30 \mu \mathrm{g} / \mathrm{kg} /$ dose (nasogastric tube/oral) and dobutamine infusion $(5-15 \mu \mathrm{g} / \mathrm{kg} / \mathrm{min})$. Pulmonary edema was treated with oxygen, prazosin, dobutamine infusions, furosemide and by mechanical ventilation, when indicated.

Cases with myocarditis are followed-up at day 5, 2 weeks, 1 month, 3 months and 6 months after the discharge clinically and were subjected to appropriate investigations. Echocardiogrphy was done by a single person to avoid inter-observer bias.

Analysis of the data was done using IBM Corp. Released 2010. IBM SPSS Statistics for Windows, Version 19.0. Armonk, NY: IBM Corp. The following statistical values were determined:

- Mean and standard deviation (SD) to describe quantitative data

- Student's t-test was used to compare means between quantitative data to determine the probability $(P)$ (significance) values

- For all tests, a $P<0.05$ was considered as significant, and $P<0.01$ was considered highly significant.

\section{Results}

Scorpion sting cases constituted 50 out of 1830 admissions during the period of 1 year (December 2009-November 2010.) in a tertiary care hospital in this study in Andhra Pradesh, India. Mean age of patients was 6.78 years with a SD of 4.42 and the mode was 3 years as shown in Table 1. Maximum cases were in the age groups of $0-3$ years and 7-9 years. The youngest case was a 4-month-old infant and the oldest was a 16 -year-old child. There was slight male preponderance $58 \%$ versus $42 \%$. Geographically $48(96 \%)$ cases came from rural areas. Table 2 deals with clinical signs and complications. Priapism was noted in 7 (14\%) and only $3(6 \%)$ had hypertension. Cardiovascular complications observed were peripheral circulatory failure (72\% cases), myocarditis and CCF (suggested by tachycardia) along with cardiomegaly, muffled heart sounds and gallop 


\begin{tabular}{lcc}
\hline $\begin{array}{l}\text { Table I: Sex, geographical area and age and symptoms } \\
\text { distribution of cases }\end{array}$ & Cases & Percentage \\
\hline Category & 29 & \\
\hline Sex & 21 & 58 \\
Male & & 42 \\
Female & 48 & \\
Geographical area & 2 & 96 \\
Rural & & 4 \\
Urban & 14 & \\
Age group (years) & 11 & 28 \\
0-3 & 13 & 22 \\
4-6 & 8 & 26 \\
$7-9$ & 4 & 16 \\
I0-I2 & & 8 \\
I3-I8 & 48 & \\
Presenting symptoms & 31 & 96 \\
Pain at site of sting & 30 & 62 \\
Salivation & 28 & 60 \\
Diaphoresis & 24 & 56 \\
Restlessness & 11 & 48 \\
Vomiting & 3 & 22 \\
Dyspnea & 2 & 6 \\
Swelling & 1 & 4 \\
Altered sensorium & 1 & 2 \\
Fever & 1 & 2 \\
Pain abdomen & & 2 \\
Convulsion & & \\
\hline & &
\end{tabular}

Table 2: Distribution of clinical signs and complications

\begin{tabular}{lcc}
\hline Signs & Number of cases & Percentage \\
\hline Cold extremities & 36 & 72 \\
Tachycardia & 36 & 72 \\
Hypotension & 33 & 66 \\
Tachypnea & 11 & 22 \\
Gallop rhythm & 10 & 20 \\
Priapism & 7 & 14 \\
Cyanosis & 3 & 6 \\
Hypertension & 3 & 6 \\
Apical systolic murmur & 2 & 4 \\
Bradycardia & 2 & 4 \\
Altered sensorium/encephalopathy & 2 & 4 \\
Myocarditis & 21 & 42 \\
Echocardiography at 24 h (n=19) & & \\
Cardiac dilatation & 19 & 100 \\
Abnormal region wall motion & 6 & 36.8 \\
Ejection fraction $<2096$ & 19 & 100 \\
Acute pulmonary edema & 11 & 22 \\
\hline
\end{tabular}

rhythm in $21(42 \%)$ cases and APE in $11(22 \%)$ cases. Out of 21 cases of myocarditis with CCF 19 responded to inotropic support of dobutamine up to $10 \mathrm{mcg} / \mathrm{kg} / \mathrm{min}$ infusion while two cases did not improve on dobutamine $15 \mathrm{mcg} / \mathrm{kg} / \mathrm{min}$ and died within $6 \mathrm{~h}$ of admission due to encephalitis and APE.

Electrocardiogram changes [Figure 1] were noted in $38(76 \%)$ cases, with sinus tachycardia being the most common finding noted in 36 cases and sinus bradycardia in two cases. ST-segment depression, tall $\mathrm{T}$-waves and T-wave inversion were seen in eight, two and six cases respectively. Low voltage complexes are noted in two cases. On repeating ECG on the $5^{\text {th }}$ day, ECG changes disappeared in most of the cases except in four cases in which T-wave inversion persisted despite clinical improvement. On follow-up T-wave inversion disappeared in one case by $1^{\text {st }}$ week follow-up ECG and in other three disappeared on 1 month follow-up.

Out of the cases which fulfilled the definition criteria for myocarditis $(n=21), 19$ cases which survived the initial $6 \mathrm{~h}$ and stabilized, were evaluated by bedside 2D echocardiography in PICU within $24 \mathrm{~h}$ of admission, and again on the $5^{\text {th }}$ day and on follow-up according to the protocol. Two cases expired within $6 \mathrm{~h}$ of admission, hence could not be evaluated. All of them (19 cases, 100\%) had evidence of left ventricular dysfunction [Table 2], in the form of left ventricular dilatation and all showed decreased left ventricular ejection fraction $(\mathrm{EF})$ below $20 \%$.

Regional wall motion abnormalities were seen in $7(36.8 \%)$ cases ranging from akinesia to global hypokinesia of the left ventricle. Three cases $(16 \%$ of cases with myocarditis) had transient mitral incompetence which was normalized on the $5^{\text {th }}$ day.

All showed improvement on the repeat echo on day 5 with improvement in the left ventricular wall motion. Echocardiographic evaluation of EF on day 1, 5, 14 and 30 showed an unmistakable trend of recovery [Figure 2]. Initial mean EF was 16.42 with SD 1.8. Lowest EF observed was $13 \%$. In seven cases, it crossed $50 \%$ on $5^{\text {th }}$ day while 3 of them were still on dobutamine $5 \mathrm{mcg} / \mathrm{kg} / \mathrm{min}$. No patient needed dobutamine support beyond 6 days. On the analysis by SPSS, there is a positive correlation between mean EF on day 1 and day 5 . The correlation coefficient was found to be 0.679 . In the paired sample $t$-test $t$ is 19.426 , and $P$ value is 0.001 which is highly significant. In 10 patients, ECG normalized on 2 week follow-up and in three it normalized at 1 month follow-up. At the end of 1 month mean EF was $60 \pm 1.5 \%$. No residual cardiac damage was detected at follow-up over 6 months.

\section{Discussion}

Common physical signs noted were restlessness, cold peripheries, tachycardia and hypotension. $72 \%$ of cases presented with "autonomic storm," characterized by cold extremities, tachycardia, hypotension $(66 \%)$ or hypertension $(6 \%)$ which is comparable to a study by Bawaskar ${ }^{[10]}$ and Biswal et al..$^{[11]}$ Incidence of hypertension in scorpion stings in Indian studies, varies from $12.6 \%$ to $29 \%$ and hypertension is usually seen within $4-8 \mathrm{~h}$ after the sting. ${ }^{[10,11]}$ In our study, it was low at $6 \%$. This 


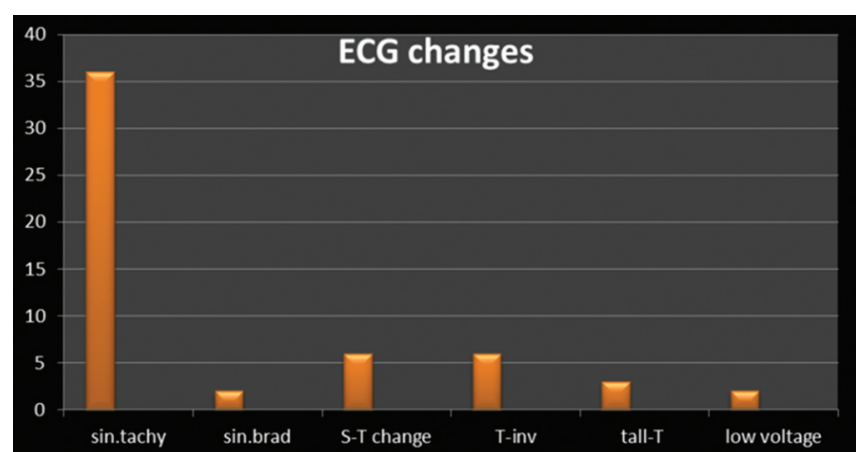

Figure I: Electrocardiogram changes in children with scorpion sting

may be due to the practice of administering Prazosin promptly in all cases on arrival at hospital mostly within 6-8 h. Bradycardia was noted in only two patients $(4 \%)$ at admission. Biswal et al. reported bradycardia in 3.5\% that is comparable. Priapism was noted in 7 (14\%) of cases and three of the cases developed myocarditis which is quite comparable to the study of Bawaskar ${ }^{[10]}$ in which priapism was $10 \%$ of cases and observed it to be one of the important cardiac premonitory signs. Gallop rhythm was found in $20 \%$ of cases. Transient apical systolic murmur was found in $6 \%$ of the cases similar to study by Biswal et al.

ECG changes were noted in $78 \%$ of cases. Earlier studies by Biswal et al., Bahloul et al. and Das et al., report that 56-99\% children had abnormal ECG following scorpion sting. ${ }^{[11-13]}$

The following abnormalities of Sinus tachycardia (commonest, 72\%), Sinus bradycardia, ST-segment depression and tall T-waves as well as low voltage complexes with sinus tachycardia being the commonest finding (36 cases) were seen. Sinus bradycardia was noted in two cases (4\%), ST-segment depression in $12 \%$ cases and tall T-waves were noted in $6 \%$ cases, low voltage complexes are noted in two cases. Santhanakrishnan ${ }^{[14]}$ reported similar observations. $\mathrm{T}$-wave inversion was noted in six cases (12\%). Bahloul et al. ${ }^{[12]}$ reported T-wave inversion in $9 \%$ of the cases. On repeating ECG on the $5^{\text {th }}$ day, ECG changes disappeared in most of the cases except in four cases in which T-wave inversion persisted despite clinical improvement. On follow-up T-wave inversion disappeared in one case by $1^{\text {st }}$ week follow-up ECG and in other three disappeared after 1 month. Murthy and Yeolekar ${ }^{[15]}$ and Diaz et al. ${ }^{[16]}$ reported similar observations.

Myocardial dysfunction leading to cardiomegaly and decreased EF was seen in $42 \%$ cases which are not much different from the study in Saudi Arabia by Kumar et al. ${ }^{[17]}$ and Das et al.${ }^{[13]}$ in Pondicherry in which $40 \%$ and $35 \%$ cases respectively had reduced EF.

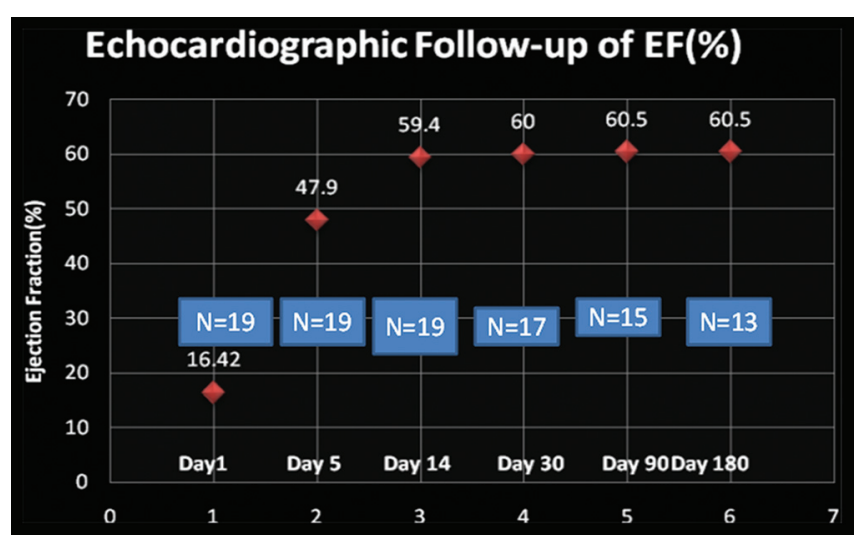

Figure 2: Serial mean left ventricular ejection fraction plotting on echocardiographic follow-up

In all the cases with CCF and myocarditis, there was a significant drop in EF. Three children (6\%) had transient mitral incompetence which disappeared on the $5^{\text {th }}$ day repeat echocardiography. This was similar to the observation by Biswal et al. ${ }^{[11]}$ in which transient myocardial infarction was seen in $2.5 \%$ cases. The regional wall motion abnormalities ranged from akinesia to gross hypokinesia of the left ventricle. Initial mean EF was $16 \%$. Lowest EF observed was 13\%. All of them showed a highly significant ( $P$ value 0.001 ) improvement on the repeat echo on day 5 . Mean EF on day 5 was $47.94 \%$. Repeat echo on $5^{\text {th }}$ day when children improved clinically showed improvement in the left ventricular wall motion also. In six of them EF normalized on $5^{\text {th }}$ day.

The mean EF on day 14 and 1 month were 59.4 and $60 \%$ respectively. This finding is in contrast with Kumar et al. ${ }^{[17]}$ in which $75 \%$ (9 out of 12) of the children with scorpion venom myocarditis, showed improvement in EF within $48 \mathrm{~h}$. This difference may be due to the fact that Indian scorpion venom is more cardiotoxic than that in Saudi Arabia. But another published study from Tunisia showed that a complete improvement with echocardiography in some patients with the scorpion envenomation continued up to 2 weeks. ${ }^{[18]}$

One important limitation of this study is that we did not use the antivenom against scorpion in our study. The antivenom against the toxins of Mesobuthus tamulus (Red Scorion) has not been found effective in comparison of prazosin. ${ }^{[19]}$ Studies from Tunisia ${ }^{[20,21]}$ and Turkey ${ }^{[22]}$ has shown excellent results with early use of antivenom.

Thus this study, being the first of its kind in evaluating myocardial functions with serial echocardiography done over 6 months, demonstrates a transient and nonstructural myocardial dysfunction caused by Indian scorpion envenomation. 


\section{Acknowledgments}

We like to take this opportunity to acnowledge Dr. Narasimha Reddy, Medical Superintendent, Dr. Sambasiva Reddy, Prof., Pediatrics and Dr. Bhaktawatsala Reddy, MD, DM (Cardiology), Consultant Cardiologist, Narayana Medical College, Nellore for the help support and guidance during this study.

\section{References}

1. Kumar CM. Scorpion sting - The challenge for intensivis. Pak Pediatr J 2008;32:192-9.

2. Chippaux JP, Goyffon M. Epidemiology of scorpionism: A global appraisal. Acta Trop 2008;107:71-9.

3. Dittrich K, Power AP, Smith NA. Scorpion sting sydrome - A ten year experience. Ann Saudi Med 1995;15:148-55.

4. Mahaba HM. Scorpion sting syndrome: Epidemiology, clinical presentation and management of 2240 cases. East Mediterr Health J $1997 ; 3: 82-9$

5. Rao AV, Ramaswamy VN. Toxic myocarditis with resultant arrhythmias due to scorpion sting. J Assoc Physicians India 1981;29:481-3.

6. Wang R, Moreau P, Deschamps A, de Champlain J, Sauvé R, Foucart S, et al. Cardiovascular effects of Buthus martensii (Karsch) scorpion venom. Toxicon 1994;32:191-200.

7. Karnad DR. Haemodynamic patterns in patients with scorpion envenomation. Heart 1998;79:485-9.

8. Mahadevan S, Choudhury P, Puri RK, Srinivasan S. Scorpion evenomation and the role of lytic cocktail in its management. Indian J Pediatr 1981;48:757-61.

9. Santhanakrishnan BR, Gajalakshmi BS. Pathogenesis of cardiovascular complications in children following scorpion envenoming. Ann Trop Paediatr 1986;6:117-21.

10. Bawaskar HS. Scorpion sting and cardiovascular complications. Indian Heart J 1977;29:228.

11. Biswal N, Bashir RA, Murmu UC, Mathai B, Balachander J, Srinivasan S. Outcome of scorpion sting envenomation after a protocol guided therapy. Indian J Pediatr 2006;73:577-82.
12. Bahloul M, Chabchoub I, Chaari A, Chtara K, Kallel H, Dammak H, et al. Scorpion envenomation among children: Clinical manifestations and outcome (analysis of 685 cases). Am J Trop Med Hyg 2010;83:1084-92.

13. Das S, Nalini P, Ananthakrishnan S, Sethuraman KR, Balachander J, Srinivasan S. Cardiac involvement and scorpion envenomation in children. J Trop Pediatr 1995;41:338-40.

14. Santhanakrishnan BR. Scorpion sting. Indian Pediatr 2000;37:1154-7.

15. Murthy RK, Yeolekar ME. Electrocardiographic changes in Acute myocarditis produced by Scorpion (Bothus tumulus) venom. Indian Heart J 1986;38:206-10.

16. Diaz P, Chowell G, Ceja G, D'Auria TC, Lloyd RC, Castillo-Chavez C. Pediatric electrocardiograph abnormalities following Centruroides limpidus tecomanus scorpion envenomation. Toxicon 2005;45:27-31.

17. Kumar EB, Soomro RS, al Hamdani A, el Shimy N. Scorpion venom cardiomyopathy. Am Heart J 1992;123:725-9.

18. Bahloul M, Ben Hamida C, Chtourou K, Ksibi H, Dammak H, Kallel H, et al. Evidence of myocardial ischaemia in severe scorpion envenomation. Myocardial perfusion scintigraphy study. Intensive Care Med 2004;30:461-7.

19. Bawaskar HS, Bawaskar PH. Utility of scorpion antivenin vs prazosin in the management of severe Mesobuthus tamulus (Indian red scorpion) envenoming at rural setting. J Assoc Physicians India 2007;55:14-21.

20. Bouaziz M, Bahloul M, Kallel H, Samet M, Ksibi H, Dammak H, et al. Epidemiological, clinical characteristics and outcome of severe scorpion envenomation in South Tunisia: Multivariate analysis of 951 cases. Toxicon 2008;52:918-26.

21. Bosnak M, Levent Yilmaz H, Ece A, Yildizdas D, Yolbas I, Kocamaz H, et al. Severe scorpion envenomation in children: Management in pediatric intensive care unit. Hum Exp Toxicol 2009;28:721-8.

22. Gokdemir M, Sezer T. Evaluation of myocardial function using tissue Doppler imaging in children with moderate scorpion envenomation. Clin Toxicol (Phila) 2013;51:156-61.

How to cite this article: Kumar CM, Naveen Prasad SV. Echocardiologic evaluation and follow-up of cardiovascular complications in children with scorpion sting in coastal South India. Indian J Crit Care Med 2015;19:42-6.

Source of Support: Nil, Conflict of Interest: None declared.

\section{New features on the journal's website}

\section{Optimized content for mobile and hand-held devices}

HTML pages have been optimized of mobile and other hand-held devices (such as iPad, Kindle, iPod) for faster browsing speed.

Click on [Mobile Full text] from Table of Contents page.

This is simple HTML version for faster download on mobiles (if viewed on desktop, it will be automatically redirected to full HTML version)

\section{E-Pub for hand-held devices}

EPUB is an open e-book standard recommended by The International Digital Publishing Forum which is designed for reflowable content i.e. the text display can be optimized for a particular display device.

Click on [EPub] from Table of Contents page.

There are various e-Pub readers such as for Windows: Digital Editions, OS X: Calibre/Bookworm, iPhone/iPod Touch/iPad: Stanza, and Linux: Calibre/Bookworm.

\section{E-Book for desktop}

One can also see the entire issue as printed here in a 'flip book' version on desktops. Links are available from Current Issue as well as Archives pages.

Click on View as eBook 